\title{
Usefulness of anti-rabphilin-3A antibodies for diagnosing central diabetes insipidus in the third trimester of pregnancy
}

\author{
Kanako Sakurai $^{1)}$, Rika Yamashita ${ }^{1)}$, Satsuki Niituma ${ }^{1)}$, Shintaro Iwama ${ }^{2), 3)}$, Yoshihisa Sugimura ${ }^{2)}$, \\ Zenei Arihara ${ }^{1)}$ and Kazuhiro Takahashi ${ }^{4)}$ \\ 1) Department of Endocrinology and Metabolism, National Hospital Organization Sendai Medical Center, Sendai 983-8520, Japan \\ 2) Department of Endocrinology and Diabetes, Nagoya University Graduate School of Medicine, Nagoya 466-8550, Japan \\ 3) Research Center of Health, Physical Fitness and Sports, Nagoya University, Nagoya 464-8601, Japan \\ 4) Department of Endocrinology and Applied Medical Science, Tohoku University Graduate School of Medicine, Sendai \\ 980-8575, Japan
}

\begin{abstract}
We report a 27-year-old pregnant woman with polyuria, polydipsia and headache in the third trimester of pregnancy. Hypernatremia $(153 \mathrm{mEq} / \mathrm{L})$, high plasma osmolality $\left(300 \mathrm{mOsm} / \mathrm{kgH}_{2} \mathrm{O}\right)$ and low urinary osmolality $(92$ $\mathrm{mOsm} / \mathrm{kgH}_{2} \mathrm{O}$ ) were observed at the admission to our hospital. Plasma arginine vasopressin (AVP) level was inappropriately low $(2.2 \mathrm{pg} / \mathrm{mL})$ compared to the high plasma osmolality. Plasma AVP responses to hypertonic-saline infusion were blunted, and her urine osmolality increased in response to desmopressin. The diagnosis of central diabetes insipidus was made from these results. Magnetic resonance imaging (MRI) of hypothalamic-pituitary region demonstrated a significant enlargement of the pituitary stalk, suggesting the presence of hypophysitis. In addition, serum anti-rabphilin-3A antibodies that have been recently reported as a biomarker of lymphocytic infundibulo-neurohypophysitis, were positive. Diabetes insipidus continued after delivery, suggesting that polyuria was not mainly due to excessive vasopressinase activity or reduced renal sensitivity to AVP by prostaglandin $\mathrm{E}_{2}$ that can cause temporal polyuria during pregnancy. We therefore clinically diagnosed central diabetes insipidus due to lymphocytic infundibulo-neurohypophysitis, without performing invasive transsphenoidal pituitary biopsy. This case suggested the usefulness of anti-rabphilin-3A antibodies for the etiological diagnosis of central diabetes insipidus during pregnancy.
\end{abstract}

Key words: Diabetes insipidus, Pregnancy, Vasopressinase, Lymphocytic infundibulo-neurohypophysitis, Anti-rabphilin-3A antibodies

CENTRAL DIABETES INSIPIDUS was considered idiopathic in approximately $50 \%$ of affected subjects [1]. An important cause among them is autoimmune hypophysitis, often referred to lymphocytic hypophysitis [2]. Lymphocytic hypophysitis is classified into lymphocytic adeno-hypophysitis (LAH), lymphocytic infundibulo-neurohypophysitis (LINH), and lymphocytic pan-hypophysitis (LPH) [2].

Diabetes insipidus during pregnancy is a rare condition [3]. Its most common etiology is excessive vasopressinase activity $[3,4]$, or an increased production of renal prostaglandins (especially prostaglandin $\mathrm{E}_{2}$, $\mathrm{PGE}_{2}$ ) which may reduce renal sensitivity to AVP [5].

Submitted Jan. 22, 2017; Accepted Feb. 17, 2017 as EJ17-0028 Released online in J-STAGE as advance publication Apr. 14, 2017 Correspondence to: Kanako Sakurai, M.D., Ph.D., Department of Endocrinology and Metabolism, National Hospital Organization Sendai Medical Center, 2-8-8 Miyagino, Miyagino-ku, Sendai, Miyagi, 983-8520, Japan. E-mail: kanasakurai-dm@umin.ac.jp
Increased vasopressinase activity was caused by the excessive production in the placenta, or the insufficient hepatic degradation due to transient liver dysfunction [4]. LINH causes central diabetes insipidus and swelling of posterior pituitary and/or stalk. Cases of LINH during pregnancy or postpartum are, however, very rare [6-8]. In contrast, LAH shows a striking temporal association with pregnancy and postpartum $[9,10]$.

Rabphilin-3A has been shown to be a targeted autoantigen in LINH and autoantibodies to rabphilin-3A may therefore serve as a biomarker for the diagnosis of LINH [11]. Rabphilin-3A was expressed in AVP neurons of the hypothalamic supraoptic nucleus and the posterior pituitary [11].

Here we report a pregnant woman with central diabetes insipidus due to LINH during the third trimester of pregnancy. In this case, the test of anti-rabphilin-3A antibodies was helpful for the etiological diagnosis of central diabetes insipidus during pregnancy. 


\section{Results}

\section{Case report}

A27-year-old woman (gravida 2, para 2) was referred to our hospital in the 33rd week of gestation with the symptoms of polyuria, polydipsia and headache. The prenatal course of the pregnancy was uneventful until the 30th week of gestation, when she noted a progressive increase in her urine volume and oral intake of water (urine volume, 8 liters per day, and oral intake, 7 liters per day) at the first visit to our hospital.
Her past medical history was unremarkable. She did not have polyuria or polydipsia during her previous pregnancies, or excessive bleeding at or after delivery. She had no history of brain diseases. Her family history was negative for endocrine diseases.

On admission, she was in moderate general condition with reduced skin turgor and dry mouth. She had no visual disturbance. Blood pressure was 144/99 $\mathrm{mmHg}$, and the pulse rate was $82 / \mathrm{min}$. Laboratory test results are summarized in the Table 1. Serum sodium $(153 \mathrm{mEq} / \mathrm{L})$, serum chloride $(117 \mathrm{mEq} / \mathrm{L})$ and plasma

Table 1 Laboratory test results

\begin{tabular}{|c|c|}
\hline \multicolumn{2}{|l|}{ Biochemistry } \\
\hline AST (IU/L) & 21 \\
\hline ALT (IU/L) & 18 \\
\hline LDH (IU/L) & 175 \\
\hline T-bil (mg/dL) & 0.8 \\
\hline BUN (mg/dL) & 2 \\
\hline Cre (mg/dL) & 0.31 \\
\hline $\mathrm{Na}(\mathrm{mEq} / \mathrm{L})$ & 153 \\
\hline $\mathrm{Cl}(\mathrm{mEq} / \mathrm{L})$ & 117 \\
\hline $\mathrm{K}(\mathrm{mEq} / \mathrm{L})$ & 4 \\
\hline HbAlc $(\%)$ & 6.1 \\
\hline Glucose (mg/dL) & 89 \\
\hline Plasma osmolality $\left(\mathrm{mOsm} / \mathrm{kgH}_{2} \mathrm{O}\right)$ & 300 \\
\hline \multicolumn{2}{|l|}{ Urinalysis } \\
\hline Specific gravity & 1.002 \\
\hline Urinary osmolality $\left(\mathrm{mOsm} / \mathrm{kgH}_{2} \mathrm{O}\right)$ & 92 \\
\hline Urinary protein & $(-)$ \\
\hline \multicolumn{2}{|l|}{ Hormones } \\
\hline $\mathrm{GH}(\mathrm{ng} / \mathrm{mL})$ & 13.4 \\
\hline Insulin like growth factor-1 (IGF-1) $(\mathrm{ng} / \mathrm{mL})$ & $203(141-328)$ \\
\hline $\mathrm{ACTH}(\mathrm{pg} / \mathrm{mL})$ & 27.3 \\
\hline Cortisol $(\mu \mathrm{g} / \mathrm{dL})$ & 21.6 \\
\hline Dehydroepiandrosterone sulfate (DHEA-S) ( $\mu \mathrm{g} / \mathrm{dL})$ & $105.5(18-391)$ \\
\hline LH (mIU/mL) & 0.15 \\
\hline FSH (mIU/mL) & 0.05 \\
\hline PRL (ng/mL) & 157.3 \\
\hline $\mathrm{TSH}(\mu \mathrm{IU} / \mathrm{mL})$ & 0.958 \\
\hline Free T3 (pg/mL) & 2.92 \\
\hline Free T4 (ng/dL) & 1.2 \\
\hline Arginine vasopressin (AVP) (pg/mL) & 2.2 \\
\hline \multicolumn{2}{|l|}{ Others } \\
\hline Soluble interleukin-2 receptor $(\mathrm{U} / \mathrm{mL})$ & $293.1(332.9-586.7)$ \\
\hline Angiotensin converting enzyme (ACE) (IU/L) & $8.3(7-25)$ \\
\hline $\operatorname{IgG}(\mathrm{mg} / \mathrm{dL})$ & 839 \\
\hline IgG4 (mg/dL) & $28.4(4.8-105)$ \\
\hline Human chorionic gonadotropin $\beta(\mathrm{hCG} \beta) *(\mathrm{ng} / \mathrm{mL})$ & $<0.1(0-0.1)$ \\
\hline$\alpha$-fetoprotein $(\mathrm{AFP}) *(\mathrm{ng} / \mathrm{mL})$ & $1.2(0-6.2)$ \\
\hline
\end{tabular}

* The test was performed after delivery. The ranges of reference values are indicated in the parentheses. 
osmolality $\left(300 \mathrm{mOsm} / \mathrm{kgH}_{2} \mathrm{O}\right)$ were high whereas the specific gravity (1.002) and osmolality $(92 \mathrm{mOsm} /$ $\mathrm{kgH}_{2} \mathrm{O}$ ) of urine were in the lower range. Blood sample for AVP was collected into tube containing o-phenanthroline (a vasopressinase inhibitor) and plasma AVP level was measured by radioimmunoassay using a AVP kit Yamasa (Yamasa Shoyu Corporation, Choshi, Japan) [12]. Plasma AVP level (2.2 pg/mL; reference range, less than $2.8 \mathrm{pg} / \mathrm{mL}$ ) was not elevated in spite of hypernatremia and high plasma osmolality. A test of anti-rabphilin-3A antibodies (a biomarker of the LINH), which were detected as previously reported [11], was positive (Fig. 1). The results of the other laboratory tests were normal, including liver and renal function tests, basal levels of anterior pituitary hormones, soluble interleukin 2 receptor, angiotensin-converting enzyme (ACE), and IgG4. Magnetic resonance imaging (MRI) of hypothalamic-pituitary region performed without administration of gadolinium contrast medium in the 33rd week of gestation demonstrated a significant enlargement of the pituitary stalk that are characteristics of hypophysitis, and the lack of bright spot in the posterior pituitary on T1-weighted image (Fig. 2A-2D).

Hypertonic-saline-infusion test was performed in the 36th week of gestation, followed by desmopressin challenge test on the same day. Her plasma AVP response to hypertonic-saline infusion was blunted (from $2.2 \mathrm{pg} /$ $\mathrm{mL}$ at $0 \mathrm{~min}$ to $4.2 \mathrm{pg} / \mathrm{mL}$ at $120 \mathrm{~min}$ ) (Fig. 3), and her urine osmolality increased in response to desmopressin (from $494 \mathrm{mOsm} / \mathrm{kgH}_{2} \mathrm{O}$ at $0 \mathrm{~min}$ to $644 \mathrm{mOsm} /$ $\mathrm{kgH}_{2} \mathrm{O}$ at $60 \mathrm{~min}$ and $678 \mathrm{mOsm} / \mathrm{kgH}_{2} \mathrm{O}$ at $120 \mathrm{~min}$ ). The diagnosis of partial central diabetes insipidus was made from these test results. Subsequently, treatment with desmopressin was initiated $(10 \mu \mathrm{g}$ per day, intranasally), and her daily urine volume was reduced to less than 3 liters per day.

She delivered a 2,804 g female infant spontaneously during the 37 th week of gestation. Uterine contraction and lactation were normal. After delivery, diabetes insipidus continued, and treatment with desmopressin was continuously required, suggesting that polyuria was not mainly due to excessive vasopressinase activity or reduced renal sensitivity to AVP by $\mathrm{PGE}_{2}$ that can cause temporal polyuria during pregnancy $[4,5]$. A follow-up MRI performed one month after delivery (Fig. 2E-2J) showed no significant change compared to that in the 33rd week of gestation (Fig. 2A-2D). After administration of gado-

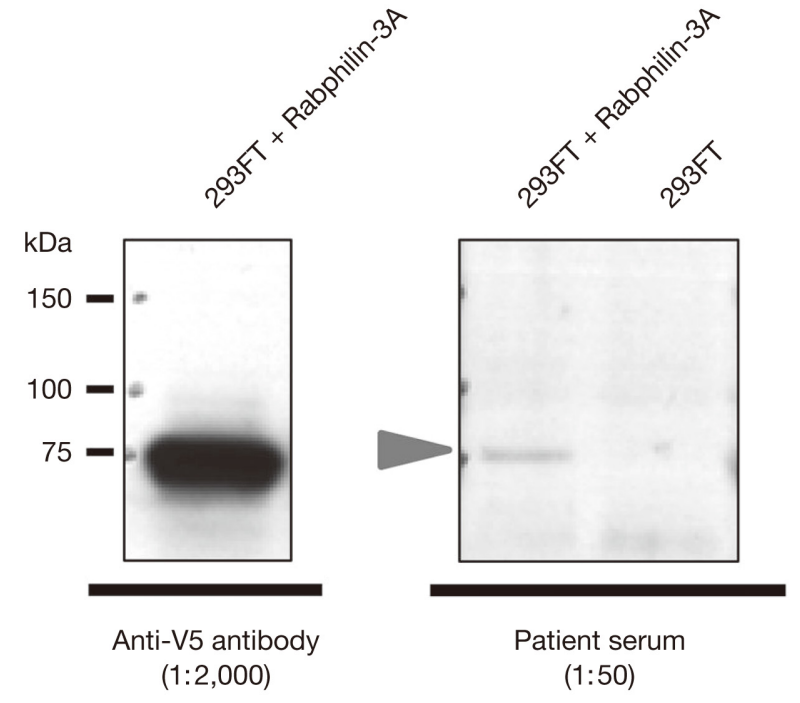

Fig. 1 Western blot detection of anti-rabphilin-3A antibodies in the patient's serum

The evaluation for the presence of anti-rabphilin$3 \mathrm{~A}$ antibodies in serum was performed as previously reported [11]. The left panel shows a positive control of recombinant full-length human rabphilin-3A (293FT + Rabphilin-3A), which was probed with an anti-V5 antibody (Invitrogen). The right panel shows 293FT + Rabphilin-3A (shown by the arrowhead) and negative control (293FT), which were probed with patient's serum at a dilution of 1:50.

linium contrast medium, the stalk and pituitary were enhanced rapidly (Fig. 2I, 2J).

Hypertonic-saline-infusion and desmopressin challenge tests were performed again 4 months after delivery. The basal level of plasma AVP and the increase of plasma AVP in response to hypertonic-saline infusion were much lower than those performed in the 36th week of gestation $(0.4 \mathrm{pg} / \mathrm{mL}$ at $0 \mathrm{~min}$ and $1.0 \mathrm{pg} / \mathrm{mL}$ at $120 \mathrm{~min}$ ) (Fig. 3), raising the possibility that the degree of inflammation by LINH progressed during this interval. Her urine osmolality increased in response to desmopressin (data not shown).

The hormonal responses of the anterior pituitary gland to gonadotropin-releasing hormone, thyrotropin-releasing hormone, corticotropin-releasing hormone, and growth hormone releasing peptide- 2 were normal after delivery (data not shown). Plasma levels of $\alpha$-fetoprotein (AFP) and human chorionic gonadotropin $\beta$ (hCG $\beta$ ) were in normal range after delivery (Table 1). Informed consent was obtained from the subject on this case report. 

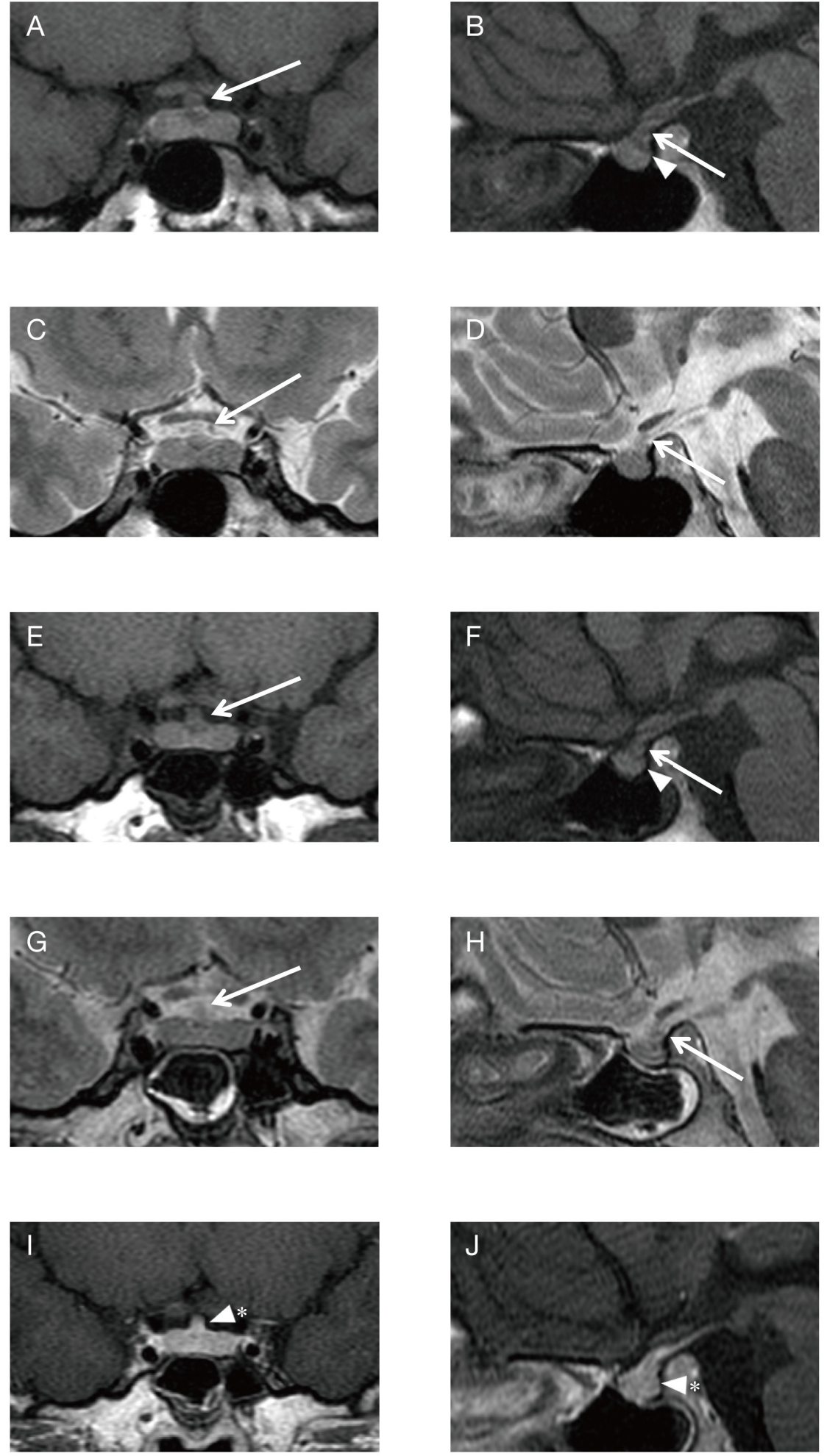

Fig. 2 MRI findings of the hypothalamic-pituitary region in the 33rd week of gestation (A-D) and one month after delivery (E-J) (A, B, E, F) T1-weighted images. (C, D, G, H) T2-weighted images. (I, J) Gadolinium-enhanced T1-weighted images. Arrows (A-H) show the significant enlargement of the pituitary stalk. Arrowheads (B, F) show the lack of bright spots of the posterior pituitary. Arrowheads with asterisks $(\mathbf{I}, \mathbf{J})$ show rapid enhancement of the stalk and the pituitary by gadolinium. 


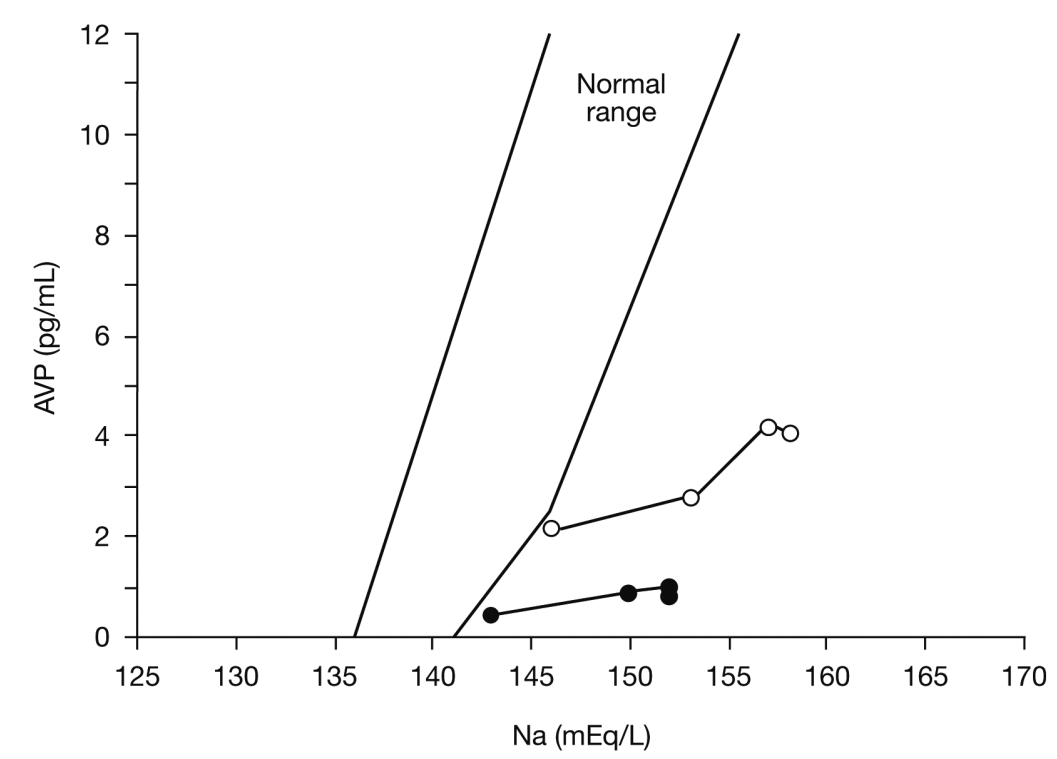

Fig. 3 Relation between plasma arginine vasopressin (AVP) concentrations and serum sodium (Na) levels before and during the infusion of $5 \%$ hypertonic saline in the 36th week of gestation (shown by open circles) and 4 months after delivery (shown by closed circles)

Normal range of plasma AVP levels is based on the data measured by the AVP-RIA kit (Mitsubishi Petrochemical Co. Ltd., Tokyo, Japan). Plasma AVP levels measured by the AVP kit Yamasa (Yamasa Shoyu Corporation, Choshi, Japan) showed a good positive correlation with those by the AVP-RIA kit (Mitsubishi Petrochemical Co. Ltd.) $(r=0.905, \mathrm{n}=111, p<0.001)$ [12].

\section{Discussion}

We reported a pregnant woman with central diabetes insipidus who was diagnosed in the third trimester. Blunted plasma AVP response to hypertonic-saline infusion and an increase in urine osmolality in response to desmopressin strongly suggested that central diabetes insipidus was the main cause of her polyuria. The finding of a significant enlargement of the pituitary stalk on the MRI supported the presence of neurohypophysitis. In addition, the presence of anti-rabphilin3A antibodies suggested LINH. The brain MRI studies, which were performed before and after delivery, showed no brain tumors, such as craniopharyngioma and germ cell tumors. Other test results did not support the diagnosis of malignant lymphoma, sarcoidosis, or IgG4-related hypophysitis in the hypothalamo-pituitary axis. We therefore clinically diagnosed central diabetes insipidus due to LINH without performing invasive transsphenoidal pituitary biopsy.

In pregnant women, the posterior pituitary is pushed posteriorly by the increased size of the anterior pituitary, and there is a loss of the hypersignal in the posterior pituitary gland because of a decrease in
AVP reserves [13]. Therefore, it is not always true that the lack of bright spot of the posterior pituitary on T1-weighted sequence during pregnancy means central diabetes insipidus. In this case, the diagnosis of central diabetes insipidus was therefore confirmed by hypertonic-saline-infusion and desmopressin challenge tests. Moreover, it is difficult to judge the pituitary stalk enlargement on MRI during pregnancy, because of an increased size of the anterior pituitary. The safety of MRI with administration of gadolinium contrast medium and invasive transsphenoidal pituitary biopsy has not been established in pregnant women. We therefore decided not to perform these investigations during pregnancy in this case. In this regard, the test of anti-rabphilin-3A antibodies was very helpful as a biomarker of LINH for the etiological diagnosis of central diabetes insipidus. In the previous report [11], anti-rabphilin-3A antibodies were detected in 22 of the $29(76 \%)$ patients with LINH, including 4 biopsy-proven samples. The specificity was $96.2 \%$ to differentially diagnose LINH from LAH or sellar/suprasellar masses. Particularly, the specificity was $100 \%$ to differentially diagnose LINH among sellar/suprasellar masses [11]. 
We present a very rare case of central diabetes insipidus due to LINH which was clinically diagnosed without performing invasive transsphenoidal pituitary biopsy during the third trimester of pregnancy. However, it should be noted that we need to follow up the patient carefully since we cannot rule out the possibility of the tumor including germ cell tumors, particularly germinoma. In conclusion, this case supported the previous report [11] on usefulness of anti-rabphilin$3 \mathrm{~A}$ antibodies as a biomarker of LINH for the etiological diagnosis in patients with central diabetes insipidus.

\section{Disclosure Statement}

The authors declare that no competing financial interests exist.

\section{References}

1. Di Iorgi N, Allegri AE, Napoli F, Calcagno A, Calandra $\mathrm{E}$, et al. (2014) Central diabetes insipidus in children and young adults: etiological diagnosis and long-term outcome of idiopathic cases. J Clin Endocrinol Metab 99: 1264-1272.

2. Caturegli P, Newschaffer C, Olivi A, Pomper MG, Burger PC, et al. (2005) Autoimmune hypophysitis. Endocr Rev 26: 599-614.

3. Durr JA, Lindheimer MD (1996) Diagnosis and management of diabetes insipidus during pregnancy. Endocr Pract 2: 353-361.

4. Yamanaka Y, Takeuchi K, Konda E, Samoto T, Satou A, et al. (2002) Transient postpartum diabetes insipidus in twin pregnancy associated with HELLP syndrome. $J$ Perinat Med 30: 273-275.

5. Bernheim J, Shapira J, David F, Behari C, Gelerntner I, et al. (1986) Renal prostaglandins E2 and F2 alpha throughout normal human pregnancy. Eur J Clin Invest 16: 113-116.

6. Van Havenbergh T, Robberecht W, Wilms G, Van Calenbergh F, Goffin J, et al. (1996) Lymphocytic infundibulohypophysitis presenting in the postpartum period: case report. Surg Neurol 46: 280-284.

7. Leggett DA, Hill PT, Anderson RJ (1999) 'Stalkitis' in a pregnant 32-year-old woman: a rare cause of diabetes insipidus. Australas Radiol 43: 104-107.

8. Wada Y, Hamamoto Y, Nakamura Y, Honjo S, Kawasaki Y, et al. (2011) Lymphocytic panhypophysitis: its clinical features in Japanese cases. Jpn Clin Med 2: 15-20.

9. Asa SL, Bilbao JM, Kovacs K, Josse RG, Kreines K (1981) Lymphocytic hypophysitis of pregnancy resulting in hypopituitarism: a distinct clinicopathologic entity. Ann Intern Med 95: 166-171.

10. Baskin DS, Townsend JJ, Wilson CB (1982) Lymphocytic adenohypophysitis of pregnancy simulating a pituitary adenoma: a distinct pathological entity. Report of two cases. J Neurosurg 56: 148-153.

11. Iwama S, Sugimura Y, Kiyota A, Kato T, Enomoto A, et al. (2015) Rabphilin-3A as a targeted autoantigen in lymphocytic infundibulo-neurohypophysitis. J Clin Endocrinol Metab 100: E946-954.

12. Tanaka S, Urakami A, Mizuno H, Togashi K (2015) Development and evaluation of RIA for the detection of plasma AVP. Jpn J Med pharm Sci 72: 1379-1388 (In Japanese).

13. Aleksandrov N, Audibert F, Bedard MJ, Mahone M, Goffinet F, et al. (2010) Gestational diabetes insipidus: a review of an underdiagnosed condition. J Obstet Gynaecol Can 32: 225-231. 